\title{
A New Method of Critical Failure Monitoring for the Heterogeneity Material Friction Welding Specimens Applying Multiple Physical Signals
}

\author{
Zhang Yubo, Xu Binshi, Wang Haidou, He Pengfei, Xing Zhiguo \\ National Key Laboratory for Remanufacturing, Academy of Armored Forces Engineering, Beijing 100072, China
}

\begin{abstract}
Fatigue fracture is a common failure mode for dissimilar materials friction welded components. To reduce the major accidents caused by sudden fracture of friction welded parts, the present paper discussed the feasibility of the combined usage of electric resistance (ER), infrared thermograph (IRT) and acoustic emission (AE) to monitor the critical fatigue damage from the perspectives of energy dissipation and micro defects evolution. The study found that three kinds of signal could be acquired synchronously. They are non-interfering and mutual support. After entering the critical fracture stage, there exists a good mapping relationship between ER and the AE amplitude and energy for the specimens of abnormal and normal fracture. They all can be regarded as the parameters of monitoring critical failure. Although IRT is usually used to predict the fatigue limit of materials, the rapid temperature rising stage may not always be obvious near the fracture. Compared with the single signal monitoring, multi-information fusion has the higher credibility, which is beneficial to increase the service safety and reliability of friction welding parts.
\end{abstract}

Key words: failure monitoring; ER; IRT; AE; multi-information fusion

At present, friction welding has been one of key welding technologies to manufacture the components with heterogeneity materials, such as the valves and the oil drill pipes with excellent quality, low consumption and high efficiency ${ }^{[1,2]}$. However, the strength and the toughness of welded joints are relatively low. The fatigue fractures usually happen at the welding joints, which may induce tremendous destruction to the equipment. Consequently, it is necessary to research a reliable method of fatigue monitoring to increase the security of equipment operating.

IRT (infrared thermograph) is a real-time, non-contact technique, which allows the detection of heat waves generated by thermo-mechanical coupling. It has been used to determine the location of fatigue damage $\mathrm{e}^{[3,4]}$ and predict the fatigue limit rapidly ${ }^{[5-8]}$. When a fatigue crack is formed, the maximum temperature can be observed at its crack tip. The position of maximum temperature increasing will keep on changing with the growing crack which helps to detect the position of $\operatorname{crack}^{[3,4]}$. In the fatigue process, when the load is lower than the fatigue limit $\sigma_{\mathrm{e}}$, the surface temperature of specimen does not change basically. However, as the load exceeds $\sigma_{\mathrm{e}}$, the temperature changes obviously. As a result, three typical phases of the temperature change can be found, including initial thermal gradient, temperature stabilization and final rapid increase of temperature until fracture ${ }^{[6,7]}$. The higher the applied stress amplitude, the higher the stationary temperature increases ${ }^{[8]}$. Though IRT can locate fatigue damage point, follow propagation of macro crack and predict fatigue limit, it is not sensitive for detecting the dislocation movement and the crack initiation.

$\mathrm{AE}$ (acoustic emission) is sensitive to the movement of micro defects. It is widely used to detect the micro plastic deformation, crack initiation, phase transformation ${ }^{[9-11]}$ and so on. Many studies ${ }^{[12-16]}$ showed that dislocation activities were

Received date: June 01,2015

Foundation item: "973" Project (2011CB013405); Distinguished Young Scholars of National Natural Science Foundation of China (51125023)

Corresponding author: Wang Haidou, Ph. D., Professor, National Key Laboratory for Remanufacturing, Academy of Armored Forces Engineering, Beijing 100072, P. R. China, Tel: 0086-10-66718475, E-mail: wanghaidou@aliyun.com 
the primary AE source for metals. However, the AE intensity is usually low for ductile materials, because much of the distortion energy is dissipated by the developing dislocations around the crack tip ${ }^{[17]}$. In addition, due to the high sensitivity of $\mathrm{AE}$ sensors, $\mathrm{AE}$ signal is easy to be influenced by external mechanical noise.

The electrical resistance (ER) depends on the specific electrical resistivity of each individual material. And ER is related to the defect density, so it is influenced by dislocation, micro cracks and micro holes etc. ${ }^{[18-20]}$. These micro defects would induce the increment of the ER through scattering electrons. Some researches ${ }^{[20,21]}$ indicated that the ER was also measurable in the load-free state and could be used as a parameter to describe the fatigue damage. However, the temperature increasing in fatigue test may affect ER.

All of IRT, AE and ER are independent and helpful tools to monitor the fatigue damage process, but only one technology usually has its limitation for complex work environment.

To improve the veracity of fatigue monitoring of friction welding components, a method of fatigue monitoring by combining these three non-destructive inspection technologies was discussed in the present paper. We examined whether these three kinds of signals could be collected simultaneously and dynamically in a fatigue test. And then, the changing character of every physical signal and their mapping relationship were researched.

\section{Experiment}

Three samples were made directly by actual exhaust valves which were made by friction welding with two different materials $5 \mathrm{Cr} 21 \mathrm{Mn} 9 \mathrm{Ni} 4 \mathrm{~N}(21-4 \mathrm{~N})$ and $4 \mathrm{Cr} 9 \mathrm{Si} 2$. The shape and dimension of specimens are shown in Fig.1. The trough located at the end of sample was used to place the AE sensor, which can prevent the AE probe from being destroyed. The elastic limit $\sigma_{\mathrm{e}}$ of these friction welding samples was about 743 $\mathrm{MPa}$, and the breaking strength $\sigma_{\mathrm{b}}$ was about $1081 \mathrm{MPa}^{[22]}$.

The monitoring system was composed of ER, IRT and AE systems as shown in Fig.2. The ER was detected by a micro resistance measurement instrument with dynamic data acquisition software coded by the authors. The highest sensitivity was $10 \mu \Omega$. Besides, supplying its four-pole circuit could

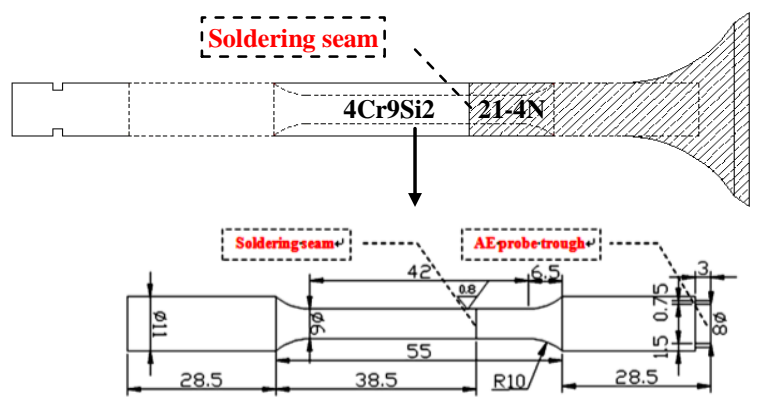

Fig.1 Details of standard specimen (mm)

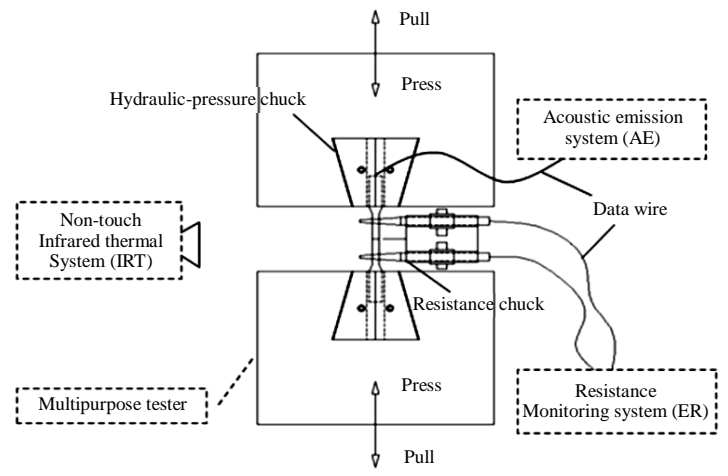

Fig.2 Manifold signals monitoring system

eliminate the effect of contact resistance to obtain true resistance. The surface temperature of specimen was detected by a thermal infrared imager with a high sensitivity of $0.035{ }^{\circ} \mathrm{C}$ at $30{ }^{\circ} \mathrm{C}$. AE signal was monitored by a two-channel $\mathrm{AE}$ system. The resonant frequency of $\mathrm{AE}$ monitor probe was $140 \mathrm{kHz}$ with 18 bit AE signal. The threshold value was set to $40 \mathrm{~dB}$.

The fatigue test was performed by the servo-hydraulic fatigue system at a test frequency of $18 \mathrm{~Hz}$ and a stress ratio of $R=-1$. In addition, square wave was chosen. Beginning from the minimum stress amplitude $390 \mathrm{MPa}$, an increment $\Delta \sigma$ of 7 $\mathrm{MPa}$ was added to the cycle stress when the cycle count reached 15000 times until fracture, as shown in Fig.3.

\section{Results and Discussion}

\subsection{Fracture analysis}

The fatigue fractures of all samples occurred near the welding seam. Near the fracture face, there is no necking. Sample 1, representing the first situation, ruptured abnormally, its fracture is flat (Fig.4a). And the second case such as sample 2 has the shear lips (Fig.5a). The fractures possess typical fatigue features such as crack initiation sites, crack propagation sites and final fracture sites (Fig.4a and Fig.5a). Obvious shell lines (Fig.4b) and the remained second cracks (Fig.4c and Fig.5c) are found in the second fatigue spreading area, which are perpendicular to the crack spreading direction

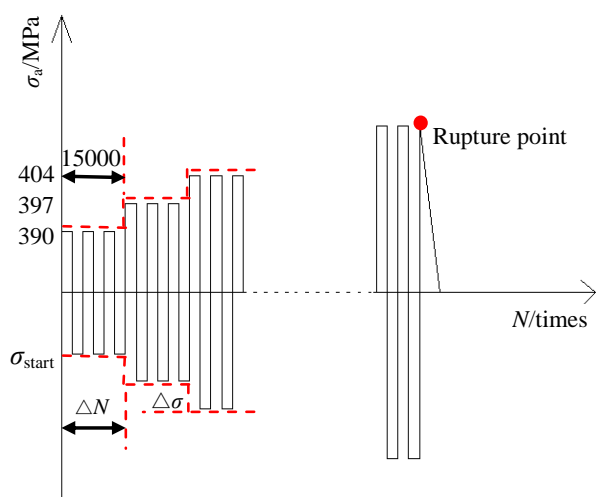

Fig.3 Sketch of loading process 


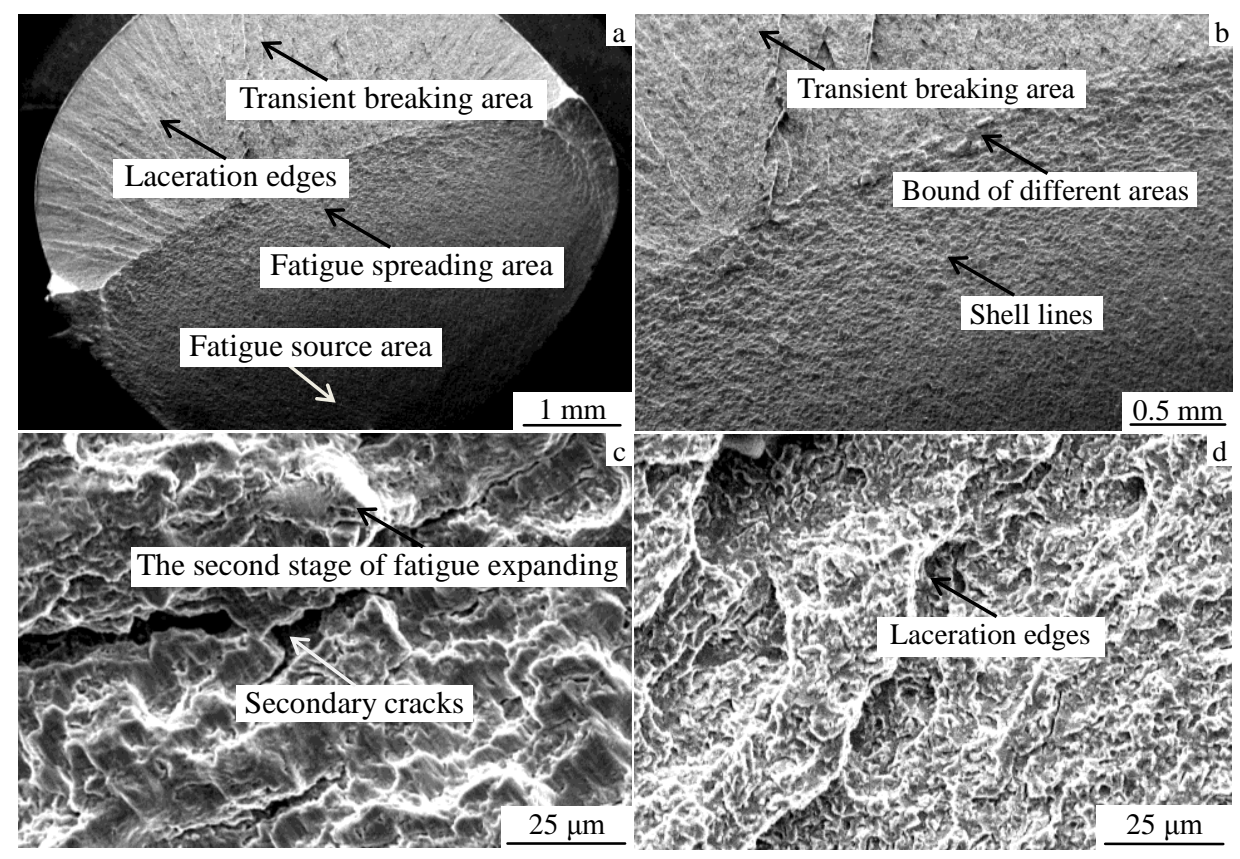

Fig.4 SEM images in different areas of fatigue fracture for sample 1: (a) typical fatigue areas, (b) shell lines, (c) secondary cracks, and (d) laceration edges

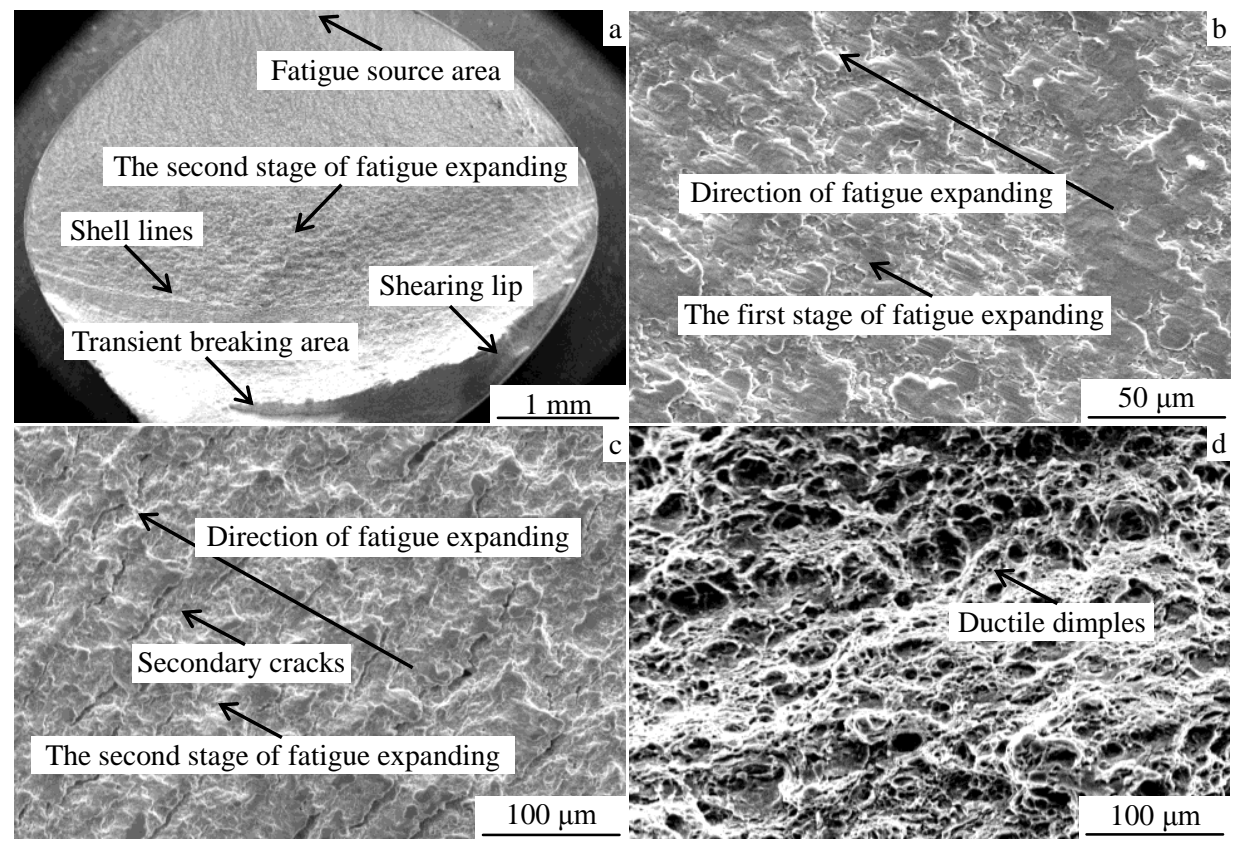

Fig.5 SEM images in different areas of fracture for sample 2: (a) typical fatigue areas, (b) direction of crack expanding, (c) secondary cracks, and (d) dimples

(Fig.5b). All these samples belong to fatigue fracture. The sample 1 presents the characteristic of quasi-cleavage fracture, because its final fracture site has macroscopic laceration edges and a few microscopic ductile dimples (Fig.4d). The quasi-cleavage fracture is a transition mode between cleavage fracture and ductile-dimple fracture, belonging to a kind of brittle fracture ${ }^{[23]}$. While the final fracture sites of the other two samples have typical ductile dimple morphology (Fig.5d), showing good toughness, and they belong to normal fatigue fracture.

\subsection{Analysis of dynamic signals for abnormal fracture}

There is a favorable mapping relationship among ER, IRT and AE signals. Due to signals of all samples possessing good repeatability, the canonical signals of one sample can reflect 
integral signal character. The ER is affected comprehensively by non-damage factors such as the change of temperature, axial elongation and section shrink, as well as damage factors such as dislocations and micro cracks ${ }^{[18,19]}$. Axial elongation and section shrink can be ignored in fatigue damage process. The ER of metal generally increases with temperature increasing. The formula of the resistance temperature coefficient TCR is as follows:

$$
\overline{T C R}=\left(R_{2}-R_{1}\right) /\left[R_{1}\left(T_{2}-T_{1}\right)\right]
$$

The average $T C R$ of the sample is about $0.005^{[22]}$. The ER is unchanged (Fig.6a) basically before the critical breaking point $\mathrm{a}_{1}$ at the load of $502 \mathrm{MPa} . \Delta R_{11}$ is about $0.005 \mathrm{~m} \Omega$, and the corresponding $\Delta T_{11}$ is about $1.75^{\circ} \mathrm{C}$ (Fig.6b).

For the sample 1 with the original ER of $0.55 \mathrm{~m} \Omega$, when the temperature increases by $1.75{ }^{\circ} \mathrm{C}$, the corresponding $\Delta R$ is about $0.0048 \mathrm{~m} \Omega$ according to formula (1), which is close to $\Delta R_{11}$. So there are no micro-defects at this time, which can be proved by synchronous AE signals. The AE signal amplitudes are lower than $50 \mathrm{~dB}$ (Fig.6c), and their corresponding energy is close to zero (Fig.6d), indicating these AE signals are mainly produced by mechanical noise and the friction between grip head and the sample.

After the critical point $a_{1}$, the rapid rising stage of ER comes. From $\mathrm{a}_{1}$ to the fracture point, $\Delta R_{12}$ is about $0.025 \mathrm{~m} \Omega$ (Fig.6a), while $\Delta T_{12}$ is about $0.25{ }^{\circ} \mathrm{C}$ (Fig.6b). It is obvious that the influence of $\Delta T_{12}$ on the ER can be ignored. Therefore, $\Delta R_{12}$ is mainly caused by micro defects proliferation, which could be proved by the high-amplitude AE signals in this stage. When reaching the critical point $\mathrm{a}_{1}$, the AE signals with above $50 \mathrm{~dB}$ (Fig.6c), and the higher energy (Fig.6d), begin to emerge abundantly, which reflect the process of crack initiation and expansion etc. ${ }^{[12-16]}$. As shown in Fig.6, in the critical fracture stage, the ER and AE signals have an obvious corresponding relation. Nevertheless, the mapping relation between ER and IRT signal is not obvious. The fast-increase stage of IRT signal does not appear. It indicates that sample 1 belongs to abnormal brittle fracture, which is consistent with the fracture analyses. The method of multi-information fusion including ER, IRT and AE signals can monitor the abnormal critical failure.

\subsection{Analysis of dynamic signals for normal fracture}

The final fracture areas of the normal fractures usually have typical ductile dimple morphology for ductile materials.

Under the critical load of $558 \mathrm{MPa}$, the ER of sample 2 is constant basically before the critical breaking point $\mathrm{a}_{2}$, with $\Delta R_{21}$ about $0.04 \mathrm{~m} \Omega$ (Fig.7a), and the corresponding $\Delta T_{21}$ about $6{ }^{\circ} \mathrm{C}$ (Fig.7b). According to formula (1), for the sample 2 with the original resistance of $0.51,0.0153 \mathrm{~m} \Omega$ is caused by $\Delta T_{21}$, and the surplus $0.0247 \mathrm{~m} \Omega$ is possibly caused by dislocations and a small quantity of slips. This can be proved by $\mathrm{AE}$ result. There is a great deal of $\mathrm{AE}$ signals with the amplitude above $50 \mathrm{~dB}$ before the critical breaking point (Fig.7c). Many AE signals already have some energy (Fig.7d). It illustrates that dislocations propagate quickly and some
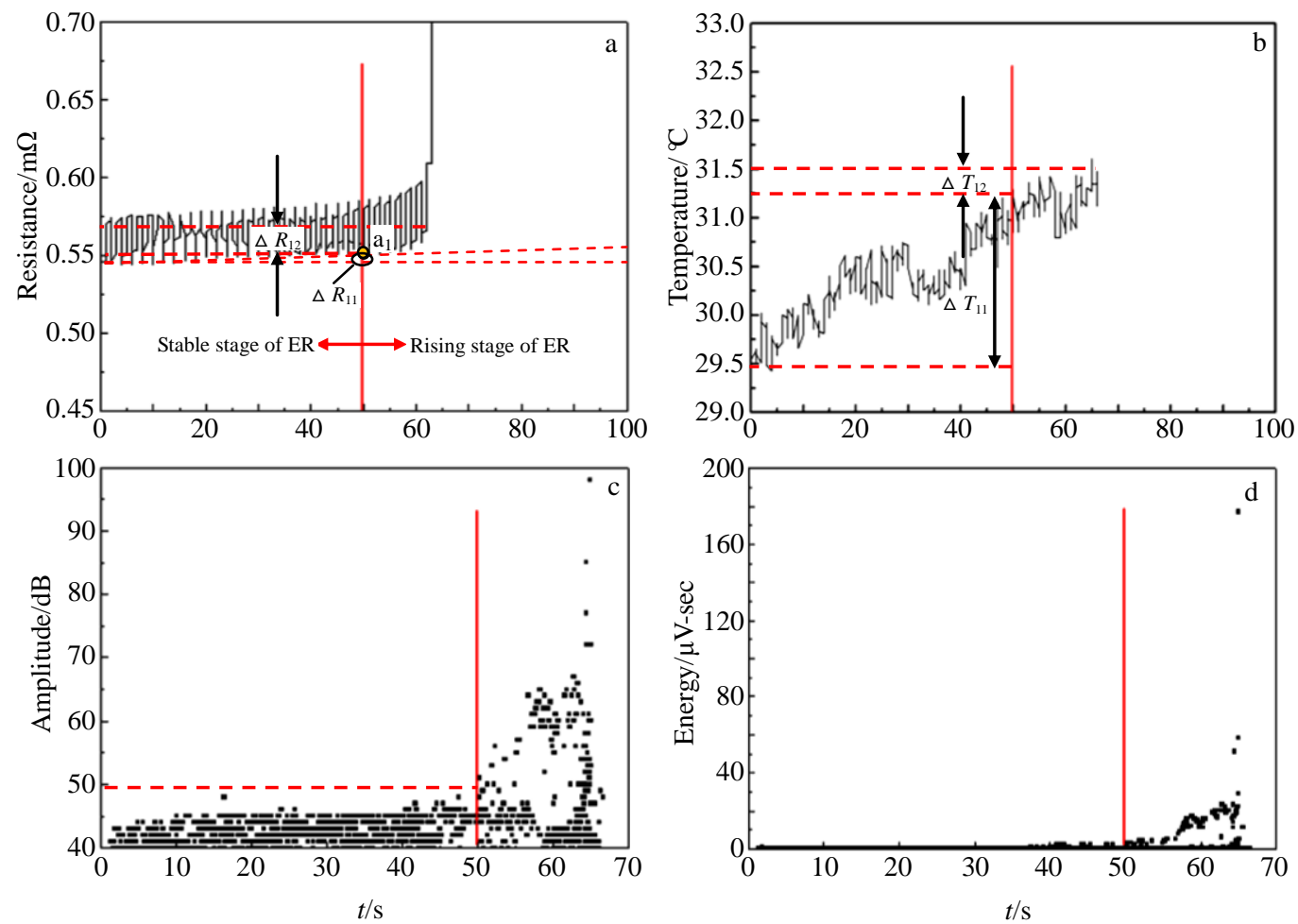

Fig.6 Mapping relationship of ER, IRT and AE signals of sample 1 (abnormal fracture) under the critical load: (a) ER, (b) IRT, (c) AE amplitude, and (d) AE energy 

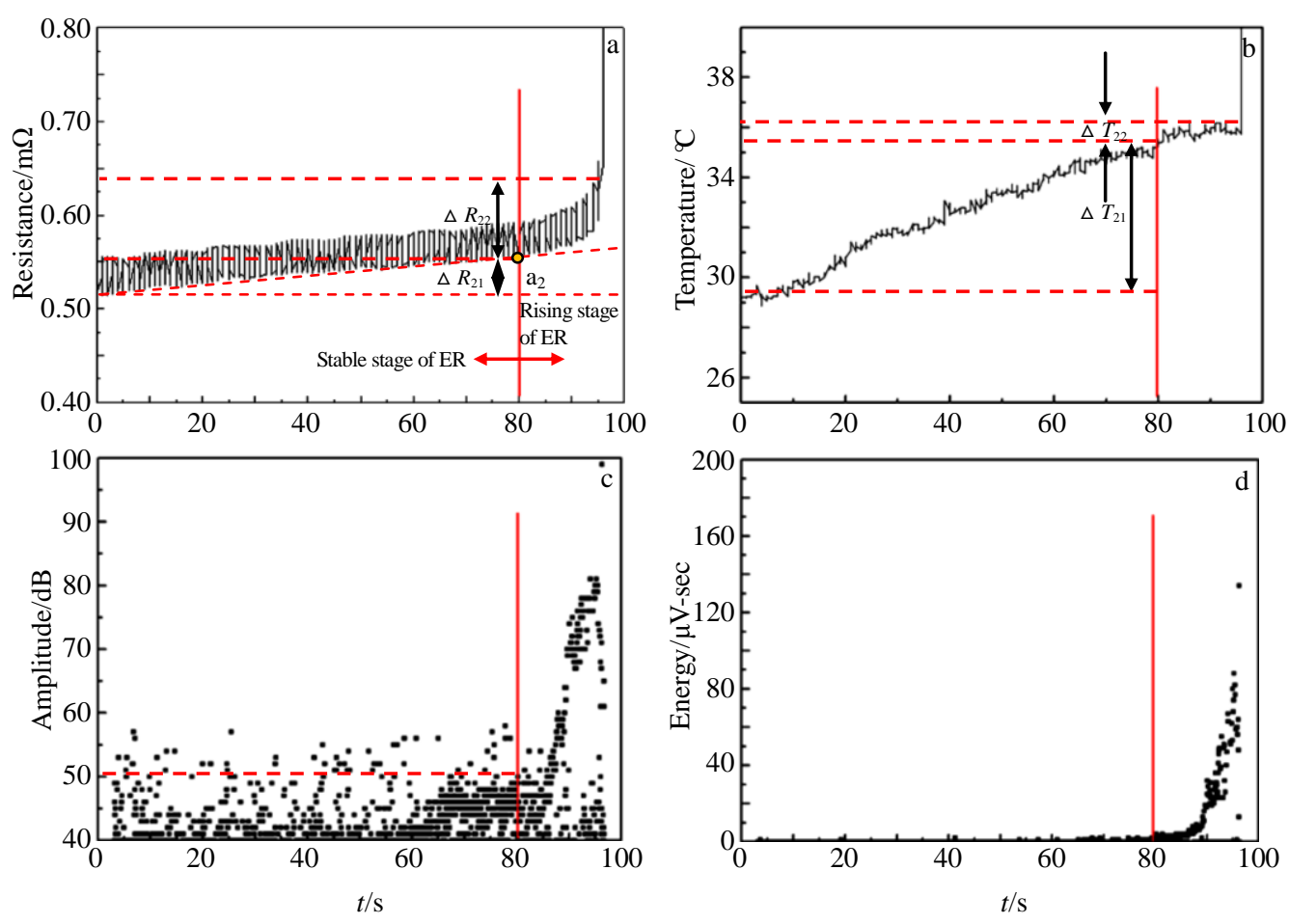

Fig.7 Mapping relationship of ER, IRT and AE signals of sample 2 (normal fracture) under the critical load: (a) ER, (b) IRT,

(c) AE amplitude, and (d) AE energy

slips begin to appear. From point $\mathrm{a}_{2}$ to fracture, $\Delta R_{22}$ is about $0.0875 \mathrm{~m} \Omega$, and the corresponding $\Delta T_{22}$ is about $0.8^{\circ} \mathrm{C}$. The temperature influence on the ER can be ignored, and the ER change is mainly caused by the electron scattering of micro-defects such as slips and micro-cracks in this stage. After exceeding point $\mathrm{a}_{2}$, the amplitude and the energy of $\mathrm{AE}$ signals increase abnormally (Fig.7c and Fig.7d), indicating that a lot of micro cracks which can release abrupt AE signals are produced and propagated. The variation curves of ER and synchronous AE signals have a good corresponding relation. When the sample is broken, the temperature increases suddenly. The transition area is not obvious, so it is difficult to warn the critical fracture only through IRT signals.

\section{Conclusions}

1) The fractures of double-materials friction welding samples present typical fatigue features. All samples broke at the heat-affected zone. The microstructure of the instantaneous breaking area represents typical dimple morphology for most samples, indicating that the heat-affected zones possess favorable ductility.

2) The evolution process of micro defects during the fatigue damage process can be monitored synchronously by three NDT technologies including ER, IRT and AE. For abnormal and normal fracture samples, the change rules of ER and AE signals have a good mapping relationship, especially after going into the critical fracture stage. The ER and the amplitude and the energy of AE signal can be regarded as characteristic parameters to alarm the critical failure. And the alarming time (15 s at least) is enough to stop machine to prevent the friction welding components from being destroyed The index increasing area of temperature does not always appear in the critical fracture stage, so it is difficult to warn the critical failure only through IRT signal, though it is usually used to estimate the fatigue limit.

3) Compared to NDT means using only one kind of monitoring technology, this multi-information fusion method possesses more superiority. It has the ability to monitor the health condition of friction welding components from manifold physical angles in the whole fatigue process.

\section{References}

1 Madhusudhan G Reddya, Venkata P Ramanab. Journal of Materials Processing Technology[J], 2012, 212: 66

2 Vishwanath S Godiganur, Shivakumar Biradar. International Journal of Research in Engineering and Technology[J], 2014, 3: 572

3 Charles J A. Experimental Mechanics[J], 1975, 15(4): 133

4 Bagavathiappan S, Lahiri B B, Saravanan T et al. Infrared Physics \& Technology[J], 2013, 60: 55

5 Kordatos E Z, Dassios K G, Aggelis D G et al. Mechanics Research Communications[J], 2013, 54: 14

6 Amiri M, Khonsari M M. International Journal of Fatigue[J], 2010, 32: 382 
7 Rosa G L, Risitano A. International Journal of Fatigue [J], 2002, 22: 73

8 Fargione G, Geraci A, Rosa G L. International Journal of Fatigue [J], 2002, 24: 19

9 Roy H, Parida N, Sivaprasad S et al. Materials Science and Engineering $A[\mathrm{~J}], 2008,486: 571$

10 Shea M M. Materials Science and Engineering[J], 1984, 64: 6

11 Jayakumar T, Mukhopadhyay C K, Venugopal S et al. Journal of Materials Processing Technology[J], 2005, 159: 61

12 Vinogradov A, Merson D L, Patlan V et al. Materials Science and Engineering $A[\mathrm{~J}], 2003,341: 73$

13 Barat K, Bar H N, Mandal D et al. Materials Science and Engineering $A[\mathrm{~J}], 2014,597: 45$

14 Hao S, Ramalingam S, Klamecki B E. Journal of Materials Processing Technology[J], 2000, 101: 136

15 Venkataraman B, Raj B, Mukhopadhyay C K et al. Rev Prog Quant Nondestr Eval[J], 2001, 20: 1450
16 Roy H, Parida N, Sivaprasad S et al. Materials Science and Engineering $A[\mathrm{~J}], 2008$, 486: 571

17 Grondel S, Delebarre C, Assaad J. NDT \& E International[J], 2002, 35: 146

18 Walther F, Eifler D. International Journal of Fatigue[J], 2007 , 29: 1886

19 Starke P, Walther F, Eifler D. Materials Science and Engineering $A[\mathrm{~J}], 2009,523: 247$

20 Starke P, Walther F, Eifler D. International Journal of Fatigue[J], 2006, 28: 1029

21 Walther F, Eifler D. Materials Science and Engineering $A[\mathrm{~J}]$, 2007, 468: 265

22 Zhang Yubo, Xu Binshi, Wang Haidou. Journal of Central South University[J], 2012, 19: 2708

23 Zhong Qunpeng. Fracture $[\mathrm{M}]$. Beijing: Higher Education Publishing Company, 2006: 270 (in Chinese)

\title{
异种材料摩擦焊件的多物理信息融合临界失效监测新方法
}

\author{
张玉波, 徐滨士, 王海斗, 何鹏飞, 邢志国 \\ (装甲兵工程学院 装备再制造技术国防科技重点实验室, 北京 100072)
}

\begin{abstract}
摘 要: 疲劳断裂是异种材料摩擦焊件常见的失效形式。为减少摩擦焊件突然断裂导致的重大事故, 从疲劳能量耗散和微观缺陷演化等 角度, 对联合应用微红外、声发射和微电阻无损检测技术同步动态监测摩擦焊件临界疲劳损伤的可行性进行了探讨。研究发现, 疲劳试 验过程中, 3种信号可同步采集, 互不干扰, 互相印证。进入临界断裂阶段后, 对于试件的异常和正常瘦劳断裂, 微电阻与声发射的幅 值和能量参数变化规律存在良好的映射关系, 它们均可作为预警临界断裂失效的参数。虽然红外热像技术常被用于通过监测试样温度场 的变化预测材料疲劳极限, 但指数增长式的温度快速上升阶段在临界断裂前未必出现。与单信号监测相比, 多物理信息融合健康监测预 警的可信度更高, 有利于提高摩擦焊件的服役安全性和可靠性。
\end{abstract}

关键词: 失效监测; 微电阻; 红外; 声发射; 多信息融合

作者简介: 张玉波，男，1986 年生，博士生，装甲兵工程学院装备再制造技术国防科技重点实验室，北京 100072，电话：010-66718475， E-mail: zyb86123@163.com 